\title{
The Comparison of mDCF and MFOLFOX-6 as First-Line Treatment in Metastatic Gastric Cancer
}

Yusuf Acikgoz ${ }^{1}$, Selin Aktürk Esen ${ }^{1}$, Gokhan Ucar ${ }^{1}$, Merve Dirikoc ${ }^{1}$, Yakup Ergun ${ }^{2}$, Oznur Bal ${ }^{1}$, Dogan Uncu $^{1}$

1. Medical Oncology, Health of Science Ankara City Hospital, Ankara, TUR 2. Medical Oncology, Batman City Hospital, Batman, TUR

Corresponding author: Yusuf Acikgoz, yacikgoz86@gmail.com

\begin{abstract}
Introduction: Fluoropyrimidine and platinum-based chemotherapy regimens are widely accepted for metastatic gastric cancer (GC). Because of drug toxicity, a combined two-drug cytotoxic drug regimen is recommended for first-line therapy, while three-drug cytotoxic regimens are recommended for patients with medically fit and better performance status. In this study, it was aimed to compare modified FOLFOX-6 (mFOLFOX-6) and modified DCF (mDCF) regimens in terms of survival and side effects in first-line treatment in metastatic GC.

Methods: We retrospectively reviewed the clinical record of patients with metastatic gastric or gastroesophageal junction cancer who had received mDCF or mFOLFOX- 6 as the first-line treatment, and followed up in our center between February 2013 and December 2020. The data were collected from the patients' registration database of the hospital and oncologic follow-up files of our center. In the mDCF arm, docetaxel $60 \mathrm{mg} / \mathrm{m}^{2}$ and cisplatin $60 \mathrm{mg} / \mathrm{m}^{2}$ on day 1 intravenous (i.v.) infusion, and $600 \mathrm{mg} / \mathrm{m}^{2} 5$-fluorouracil (FU) as a continuous infusion for five days were administrated every three weeks for up to six cycles. In the mFOLFOX-6 arm, $85 \mathrm{mg} / \mathrm{m}^{2}$ oxaliplatin and $400 \mathrm{mg} / \mathrm{m}^{2} \mathrm{LV}$ as an i.v. infusion over two hours and a 5-FU bolus of $400 \mathrm{mg} / \mathrm{m}^{2}$ as a 10 -minute infusion, followed by $2.400 \mathrm{mg} / \mathrm{m}^{2} 5$-FU as a 46 -hour continuous infusion were administrated every two weeks for up to six cycles. Univariate and multivariate analyses for overall survival (OS) were performed by Cox proportional hazards regression model. Survival analysis was performed by the Kaplan-Meier method with the Long-rank test. P-value $<0.05$ was considered statistically significant.
\end{abstract}

Review began 04/10/2021 Review ended 04/30/2021 Published 05/07/2021

\section{(c) Copyright 2021}

Acikgoz et al. This is an open access article distributed under the terms of the Creative Commons Attribution License CC-BY 4.0., which permits unrestricted use, distribution, and reproduction in any medium, provided the original author and source are credited.
Results: A total of 70 patients included into the study. Of those, 40 (57\%) patients had received mDCF and $30(43 \%)$ had received FOLFOX-6 regimens as first-line treatment. There were no complete responses in both groups. The partial response rate was $28 \%$ and $27 \%$ for mDCF and mFOLFOX- 6 , respectively. There was no statistically significant difference regarding treatment response for both groups $(\mathrm{p}=0.787)$. The median OS was 13.9 months ( $95 \%$ CI: 7.5-20.4) in the mDCF arm, and 10.4 months (95\% CI: 6.4-14.4) in the mFOLFOX-6 $\operatorname{arm}(\mathrm{p}=0.409)$. The median progression-free survival (PFS) was 5.2 months (95\% CI: 3.6-6.9) in the mDCF arm, and 6.4 months (3.2-9.6) in the FOLFOX- 6 arm $(\mathrm{p}=0.126)$. The ratio of dose reduction, treatment delay, and neutropenic fever were not statistically different between treatment arms.

Conclusion: The present study demonstrated that proper patient selection for metastatic GC may give rise to comparable survival rates without increased toxicity. mFOLFOX-6 and mDCF had similar response rates, OS, PFS, and side effect profiles.

Categories: Oncology

Keywords: metastatic gastric cancer, mdcf, mfolfox-6, toxicity, survival rate

\section{Introduction}

Although the incidence of gastric cancer (GC) has decreased in the USA and Western European countries in recent years, it still continues to be an important problem in Central Asian countries [1-5]. GC is the fifth most common cancer in the world and is the third in cancer-related deaths [6]. The incidence of GC may differ 15-20 times according to geographical regions [1]. While GC is the most common type of cancer in men in Japan and Korea, it is the fifteenth most common cancer-related death in the USA.

Fluoropyrimidine and platinum-based chemotherapy regimens are widely accepted for metastatic GC therapy [7]. Because of drug toxicity, a combined two-drug cytotoxic drug regimen is recommended for firstline therapy, while three-drug cytotoxic regimens are recommended for patients who are medically fit and with better performance status. Trastuzumab can be added to first-line chemotherapy with fluoropyrimidine and platinum-based agents in human epidermal growth factor receptor 2 (HER-2) positive metastatic gastric adenocarcinoma [7]. 
In this study, we aimed to compare modified FOLFOX-6 (mFOLFOX-6) and modified DCF (mDCF) regimens in terms of survival and side effects in first-line treatment in metastatic GC.

\section{Materials And Methods \\ Patients}

The data collected from the patients' registration database of the hospital and oncologic follow-up files were as follows: age at diagnosis, gender, ECOG performance score, presence of comorbid disease, baseline carcinoembryonic antigen (CEA) and CA 19-9 levels, tumor location, histological subtype, presence of liver or peritoneum metastasis, metastasis status (de novo vs recurrent), the number of metastasis, first-line treatment regimen, treatment response, treatment toxicity, and survival data.

\section{Treatment arms}

In the $\mathrm{mDCF}$ arm, docetaxel $60 \mathrm{mg} / \mathrm{m}^{2}$ and cisplatin $60 \mathrm{mg} / \mathrm{m}^{2}$ on day 1 intravenous (i.v.) infusion, and 600 $\mathrm{mg} / \mathrm{m}^{2} 5$-fluorouracil (FU) as a continuous infusion for five days were administrated every three weeks for up to six cycles.

In the mFOLFOX-6 arm, $85 \mathrm{mg} / \mathrm{m}^{2}$ oxaliplatin and $400 \mathrm{mg} / \mathrm{m}^{2} \mathrm{LV}$ as an i.v. infusion over 2 hours and a $5-\mathrm{FU}$ bolus of $400 \mathrm{mg} / \mathrm{m}^{2}$ as a 10 -minutes infusion, followed by $2.400 \mathrm{mg} / \mathrm{m}^{2} 5$-FU as a 46 -hour continuous infusion were administrated every two weeks for up to six cycles.

\section{Treatment response}

Treatment response was evaluated according to RECIST 1.1 criteria for every 12 weeks with computerized tomography (CT). According to RECIST criteria, complete response (CR) included the disappearance of all target lesions and reduction in the short-axis measurement of all pathologic lymph nodes to $\leqslant 10 \mathrm{~mm}$; partial response (PR) was defined as $\geqslant 30 \%$ decrease in the sum of the longest diameter of the target lesions compared with baseline; progressive disease (PD) was defined as $\geqslant 20 \%$ increase of at least $5 \mathrm{~mm}$ in the sum of the longest diameter of the target lesions compared with the smallest sum of the longest diameter recorded and the appearance of one or more new lesions; stable disease (SD) was considered for patients who met neither PR nor PD criteria.

Overall survival (OS) was defined as the time between the date of diagnosis of metastatic disease and the date of last control for alive patients or death from any cause. Progression-free survival (PFS) was defined as the time between the date of starting first-line treatment (mDCF or FOLFOX-6) and disease progression or death whichever occurred first.

\section{Statistical analysis}

Statistical analysis was performed by using Statistical Package for the Social Sciences Version 22.0 for Windows (IBM Corp., Armonk, NY, USA). The comparison of two groups were performed by Mann-Whitney U test and Pearson chi-square or Fisher's test for continuous and categorical variables, respectively. We used the Kaplan-Meier test for survival analysis, and outcomes were analyzed by the Log-rank test. Univariate and multivariate analyses for OS were performed by Cox proportional hazards regression model. All variables were included both into the univariate and multivariate analysis. We reported two-sided P-values, and Pvalue $<0.05$ considered statistically significant.

\section{Results}

\section{Patients characteristics}

A total of 70 patients were included into the study. Of those, 40 (57\%) patients had received mDCF and 30 (43\%) had received FOLFOX-6 regimens as first-line treatment. The median age was 60 (22-76) years, and the number of male patients was 51 (73\%). The number of patients who had a comorbid disease was 37 (53\%) among all patients. The number of patients who had gastric tumor was $63(90 \%)$, and $7(10 \%)$ patients had gastro-esophageal junction tumor. The distribution of histological subtype was as follows: intestinal type was 49 (70\%), the diffuse type was $17(24 \%)$, and mixt type was 4 (6\%). The number of patients who had de novo metastatic disease was 41 (59\%), while 29 (41\%) patients had recurrent disease.

The baseline clinical characteristics were not statistically different between treatment arms except for the presence of comorbid disease and metastasis status (Table 1). The ratio of patients who had a comorbid disease was higher in the FOLFOX arm compared to the mDCF arm ( $67 \%$ vs $42 \%, \mathrm{p}=0.045)$. The number of patients who had de novo metastatic disease was higher in the MDCF arm compared to the mFOLFOX-6 arm ( $82 \%$ vs $27 \%, \mathrm{p}<0.001)$. 


\section{Cureus}

\begin{tabular}{|c|c|c|c|c|}
\hline Number of patients & $40(57)$ & $30(43)$ & 70 & \\
\hline Median age (min-max) & $55(22-69)$ & $62(36-76)$ & $60(22-76)$ & 0.082 \\
\hline Gender & & & & 0.244 \\
\hline Male & $27(67)$ & $24(80)$ & $51(73)$ & \\
\hline Female & $13(33)$ & $6(20)$ & $19(27)$ & \\
\hline Comorbid disease & & & & $0.045^{\star}$ \\
\hline Yes & $17(42)$ & $20(67)$ & $37(53)$ & \\
\hline No & $23(58)$ & $10(33)$ & $33(47)$ & \\
\hline ECOG PS & & & & 0.680 \\
\hline 0 & $18(45)$ & $13(43)$ & $31(44)$ & \\
\hline 1 & $17(43)$ & $11(37)$ & $28(40)$ & \\
\hline 2 & $5(12)$ & $6(20)$ & $11(16)$ & \\
\hline Baseline CEA level (ng/mL); median (min-max) & $3.90(0.77-950)$ & $3.07(0.50-1004)$ & $3.50(0.50-1004)$ & 0.172 \\
\hline Baseline Ca 19-9 level (U/mL); median (min-max) & $25(0.80-1618)$ & $9.2(0.60-146)$ & $9.9(0.6-1618)$ & 0.085 \\
\hline Tumor location & & & & 0.421 \\
\hline Gastric & $35(87)$ & $28(93)$ & $63(90)$ & \\
\hline Gastro-esophageal junction & $5(13)$ & $2(7)$ & $7(10)$ & \\
\hline Histological subtype & & & & 0.865 \\
\hline Intestinal & $29(73)$ & $20(67)$ & $49(70)$ & \\
\hline Diffuse & $9(22)$ & $8(26)$ & $17(24)$ & \\
\hline Mixt & $2(5)$ & $2(7)$ & $4(6)$ & \\
\hline Metastasis status & & & & $<0.001^{*}$ \\
\hline De-novo metastasis & $33(82)$ & $8(27)$ & $41(59)$ & \\
\hline Recurrent metastasis & $7(18)$ & $22(73)$ & $29(41)$ & \\
\hline Liver metastasis & & & & 0.832 \\
\hline Yes & $15(38)$ & $12(40)$ & 27 (39) & \\
\hline No & $25(62)$ & $18(60)$ & $43(61)$ & \\
\hline Peritoneum metastasis & & & & 0.622 \\
\hline Yes & $17(42)$ & $11(37)$ & $28(40)$ & \\
\hline No & $23(58)$ & $19(63)$ & $42(60)$ & \\
\hline The number of metastasis & & & & 0.676 \\
\hline Single metastasis & $22(55)$ & $18(60)$ & $40(57)$ & \\
\hline Multiple metastases & $18(45)$ & $12(40)$ & $30(43)$ & \\
\hline The duration of treatment; median cycle (min-max) & $5(3-6)$ & $3.5(2-6)$ & $5(2-6)$ & 0.119 \\
\hline Dose reduction & & & & 0.928 \\
\hline Yes & $20(58)$ & $15(60)$ & $35(59)$ & \\
\hline No & $14(42)$ & $10(40)$ & $24(41)$ & \\
\hline Treatment delay & & & & 0.943 \\
\hline Yes & $16(47)$ & $12(48)$ & $28(48)$ & \\
\hline No & 18 (53) & $13(52)$ & $31(5$ & \\
\hline
\end{tabular}




\section{Cureus}

Neutropenic fever

\section{TABLE 1: Baseline features of both groups and all patients.}

CEA: carcinoembryonic antigen, ECOG PS: Eastern Cooperative Oncology Group Performance Status.

${ }^{*} p$-value $<0.05$ is statistically significant.

\section{Treatment response and toxicity}

The median duration of treatment was 5 (3-6) cycles and 3.5 (2-6) cycles for MDCF and mFOLFOX-6, respectively. The rate of dose reduction, treatment delay, and neutropenic fever were not statistically different between treatment arms (Table 1). There was no complete response in both groups. The partial response rate was $28 \%$ and $27 \%$ for $\mathrm{mDCF}$ and $\mathrm{mFOLFOX}-6$, respectively. There was no statistically significant difference regarding disease control rate (DCR) for both groups (0.787; Table 2).

\begin{tabular}{|c|c|c|c|}
\hline Characteristics & mDCF, n (\%) & mFOLFOX-6, n (\%) & p-Value \\
\hline Disease control rate $(\mathrm{CR}+\mathrm{PR}+\mathrm{SD})$ & $24(60)$ & $20(67)$ & 0.568 \\
\hline Progressive disease & $16(40)$ & $10(33)$ & 0.568 \\
\hline
\end{tabular}

\section{TABLE 2: Treatment response for the first-line chemotherapy.}

CR: complete response, PR: partial response, SD: stable disease.

\section{Survival analysis}

The median follow-up was 10.5 months in the mDCF arm, and 7.8 months in the mFOLFOX- 6 arm. The number of death was $56(80 \%)$ in the entire cohort at the time of final analysis. The median OS was 13.9 months (95\% CI: 7.5-20.4) in mDCF arm, and 10.4 months (95\% CI: 6.4-14.4) in mFOLFOX-6 arm ( $\mathrm{p}=0.409$; Figure 1). The median PFS was 5.2 months (95\% CI: 3.6-6.9) in the mDCF arm, and 6.4 months (3.2-9.6) in the FOLFOX-6 arm ( $\mathrm{p}=0.126$; Figure 2). 


\section{Cureus}

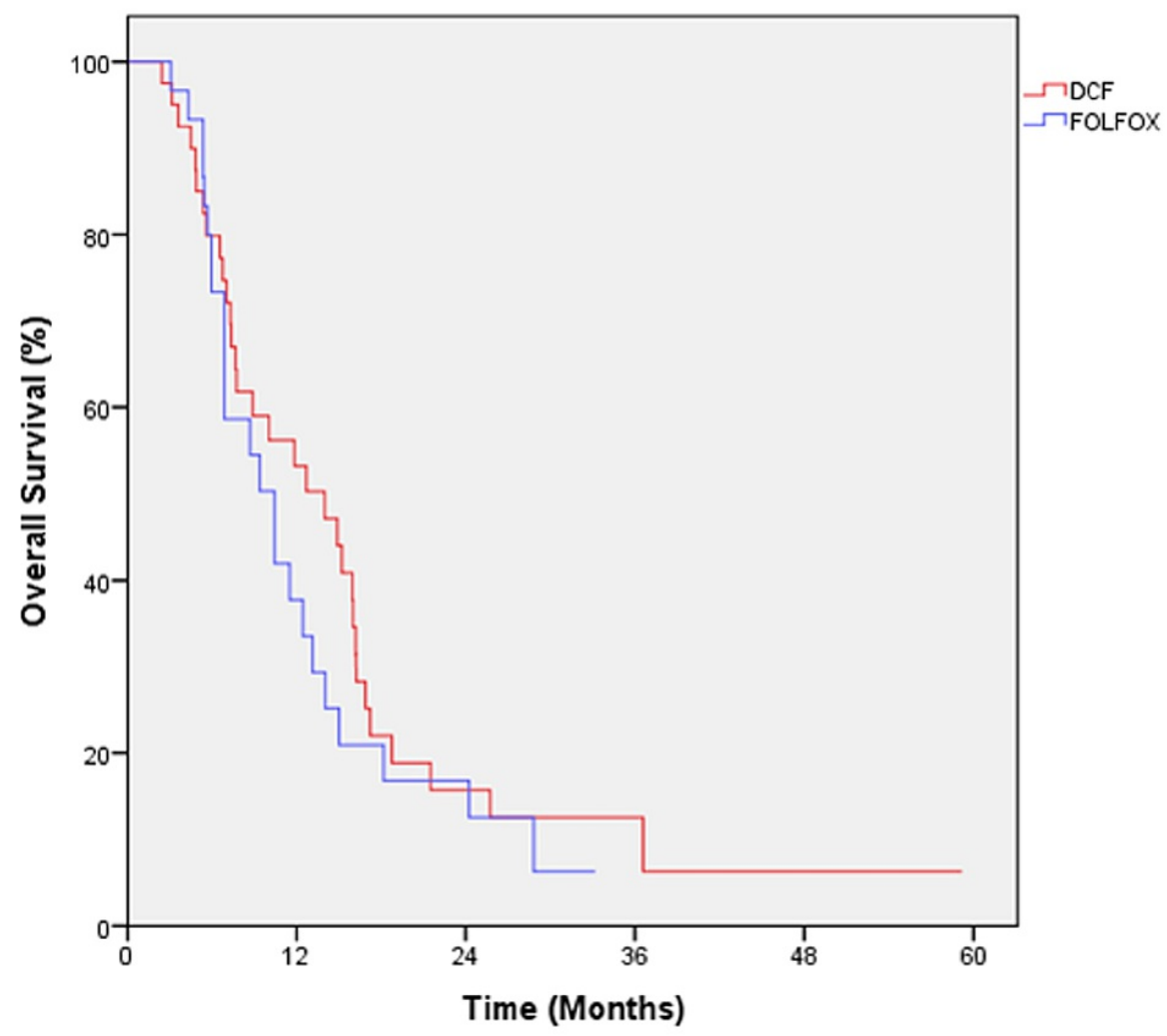

FIGURE 1: Overall survival of all patients by the first-line treatment. 


\section{Cureus}

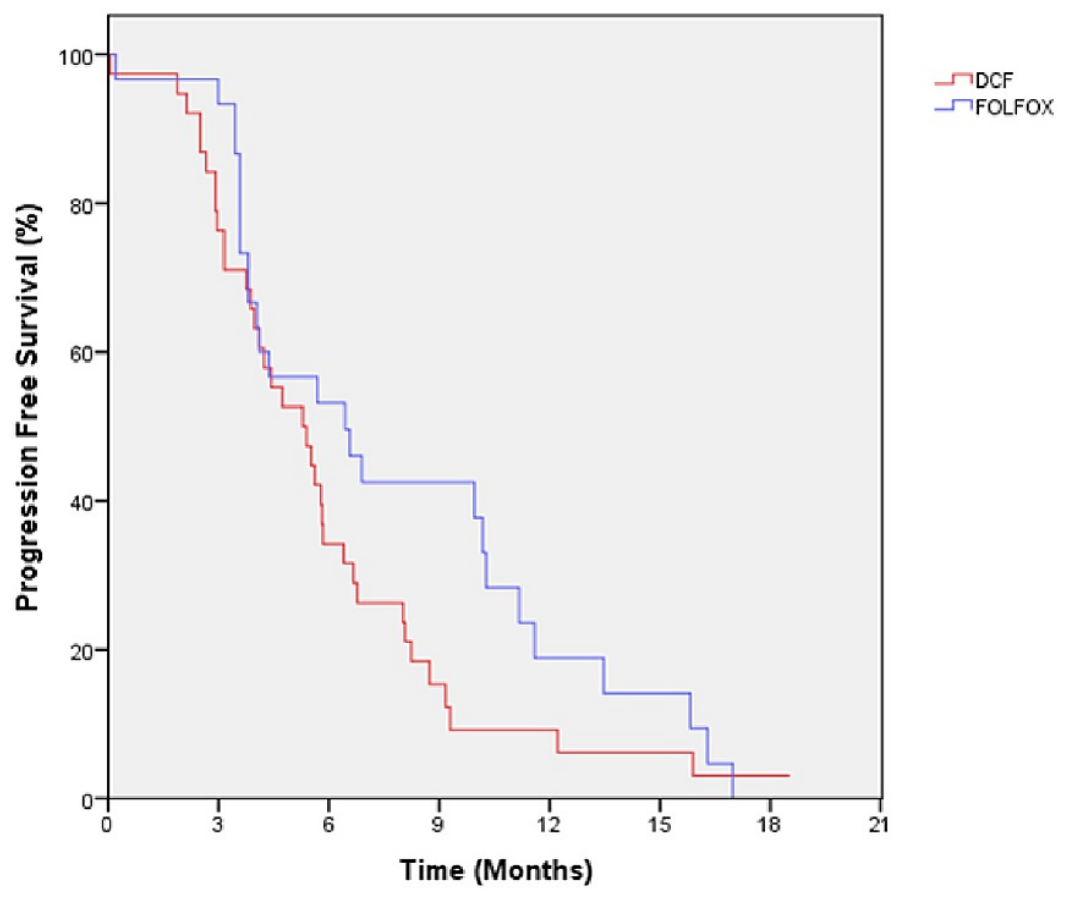

FIGURE 2: Progression-free survival of all patients by the first-line treatment.

\section{Univariate and multivariate analyses}

Univariate and multivariate analyses were performed by defining OS as an endpoint. Age, gender, comorbid disease, ECOG PS, histological subtypes, treatment arms, metastasis status, liver metastasis, peritoneum metastasis, the number of metastasis were analyzed both in univariate and multivariate analysis. According to univariate analysis patients with peritoneum, metastasis had an increased risk for death compared to those without peritoneum metastasis with a hazard ratio (HR) of 1.92 (95\% CI: 1.12-3.28; $\mathrm{p}=0.016$ ). Whereas, there were no prognostic factors for OS according to multivariate analysis. The results of univariate and multivariate analysis are shown in Table 3. 


\section{Cureus}

\begin{tabular}{|c|c|c|c|c|}
\hline \multirow{2}{*}{ Variables (n) } & Univariable & \multirow{2}{*}{ P-value } & Multivariable & \multirow{2}{*}{ P-value } \\
\hline & HR (95\% Cl) & & HR (95\% Cl) & \\
\hline Age $<60$ years $>60$ years & $10.77(0.45-1.31)$ & 0.349 & $10.94(0.47-1.87)$ & 0.866 \\
\hline \multicolumn{5}{|l|}{ Gender } \\
\hline Male (51) & 1 & \multirow{2}{*}{0.541} & 1 & \multirow{2}{*}{0.571} \\
\hline Female (19) & $1.19(0.66-2.15)$ & & $1.24(0.58-2.62)$ & \\
\hline \multicolumn{5}{|l|}{ Comorbid disease } \\
\hline Yes (37) & 1 & \multirow{2}{*}{0.682} & 1 & \multirow{2}{*}{0.885} \\
\hline No (33) & $1.11(0.65-1.90)$ & & $0.94(0.45-1.98)$ & \\
\hline \multicolumn{5}{|l|}{ ECOG PS } \\
\hline $0(31)$ & 1 & & 1 & \\
\hline $1(28)$ & $0.82(0.46-1.46)$ & 0.513 & $0.80(0.42-1.54)$ & 0.521 \\
\hline $2(11)$ & $1.45(0.67-3.13)$ & 0.337 & $1.20(0.49-2.95)$ & 0.681 \\
\hline \multicolumn{5}{|l|}{ Histological subtype } \\
\hline Intestinal (49) & 1 & & 1 & \\
\hline Diffuse (17) & $1.66(0.90-3.05)$ & 0.099 & $2.00(0.76-5.23)$ & 0.154 \\
\hline Mixt (4) & $0.91(0.21-3.79)$ & 0.898 & $0.96(0.20-4.59)$ & 0.962 \\
\hline \multicolumn{5}{|l|}{ Treatment arms } \\
\hline DCF (40) & 1 & \multirow{2}{*}{0.411} & 1 & \multirow{2}{*}{0.813} \\
\hline FOLFOX (30) & $1.25(0.73-2.14)$ & & $1.11(0.46-2.67)$ & \\
\hline \multicolumn{5}{|l|}{ Metastasis status } \\
\hline De-novo metastasis (41) & 1 & \multirow{2}{*}{0.495} & 1 & \multirow{2}{*}{0.333} \\
\hline Recurrent metastasis (29) & $1.20(0.70-2.05)$ & & $1.50(0.65-3.45)$ & \\
\hline \multicolumn{5}{|l|}{ Liver metastasis } \\
\hline Yes (27) & 1 & \multirow{2}{*}{0.907} & 1 & \multirow{2}{*}{0.266} \\
\hline No (43) & $0.96(0.56-1.65)$ & & $0.63(0.28-1.41)$ & \\
\hline \multicolumn{5}{|l|}{ Peritoneum metastasis } \\
\hline No (42) & 1 & \multirow{2}{*}{$0.016^{*}$} & 1 & \multirow{2}{*}{0.104} \\
\hline Yes (28) & $1.92(1.12-3.28)$ & & $1.75(0.89-3.45)$ & \\
\hline \multicolumn{5}{|l|}{ The number of metastasis } \\
\hline Single metastasis (40) & 1 & \multirow{2}{*}{0.568} & 1 & \multirow{2}{*}{0.509} \\
\hline Multiple metastases (30) & $1.16(0.68-1.99)$ & & $1.27(0.62-2.58)$ & \\
\hline
\end{tabular}

TABLE 3: Univariate and multivariate analysis for OS.

HR: hazard ratio, OS: overall survival, ECOG PS: Eastern Cooperative Oncology Group Performance Status.

${ }^{*} p$-value $<0.05$ is statistically significant.

\section{Discussion}

Various cytotoxic agents can be used in the metastatic GC: fluoropyrimidines (fluorouracil, capecitabine, 
and S-1), platins (cisplatin and oxaliplatin), taxanes (docetaxel and paclitaxel), anthracycline epirubicin, and irinotecan, which is a topoisomerase inhibitor [8]. Using these agents alone results in a low ORR. For example, the response is $20-40 \%$ with fluoropyrimidines [9-12], $20 \%$ with taxanes [13,14], and $20 \%$ with irinotecan [15]. Considering the toxicity, the addition of docetaxel to fluoropyrimidine and platinum-based chemotherapy in the first-line treatment is controversial [16]. Docetaxel has been used as a monotherapy and combination therapy in GC and its effectiveness has been demonstrated in several studies [17,18]. In a study, DCF (docetaxel $75 \mathrm{mg} / \mathrm{m}^{2}$ and cisplatin $75 \mathrm{mg} / \mathrm{m}^{2}$ on day 1 iv infusion, and $750 \mathrm{mg} / \mathrm{m}^{2} 5-\mathrm{FU}$ as continuous infusion for five days every three weeks) and CF (cisplatin $100 \mathrm{mg} / \mathrm{m}^{2}$ on day 1 followed by fluorouracil $1000 \mathrm{mg} / \mathrm{m}^{2} / \mathrm{d}$ for five days every four weeks) regimens were compared and the median OS was detected better in the DCF arm (9.2 months vs. 8.6 months) [19]. In the same study, rates of febrile neutropenia, > grade 3 leukopenia, and neutropenia were significantly higher in the DCF group [19]. In another phase 3 randomized study in metastatic GC patients, the effects of adding docetaxel to S-1 and cisplatin were investigated and no difference was detected between treatment outcomes [16]. In the same study, grade 3 and higher toxicity were found to be higher in the triple combination (59\% vs. $32 \%$ ).

In the literature, there are various studies comparing DCF and $\mathrm{mDCF}$ in first-line treatment in metastatic GC patients [20]. In another study comparing DCF + granulocyte colony-stimulating factor (G-CSF) and mDCF (fluorouracil $2,000 \mathrm{mg} / \mathrm{m}^{2}$ intravenously [IV] over 48 hours, docetaxel $40 \mathrm{mg} / \mathrm{m}^{2}$ IV on day 1, cisplatin 40 $\mathrm{mg} / \mathrm{m}^{2} \mathrm{IV}$ on day 3 , every two weeks), while the median OS was better in the mDCF group (18.8 $\mathrm{v} 12.6$ months; $\mathrm{P}=0.007)$, the median PFS was numerically better in the $\mathrm{mDCF}$ group, but could not reach statistical significance (mDCF, 9.7 v DCF, 6.5 months) [21]. In the same study, while grade 3-4 toxicity was observed at a rate of $90 \%$, neutropenia with a rate of $45 \%$, and febrile neutropenia in $16 \%$ in the DCF arm; grade $3-4$ toxicity was $76 \%$, neutropenia was $56 \%$, and febrile neutropenia was $9 \%$ in the mDCF arm [21].

There are limited studies comparing FOLFOX and DCF/mDCF regimens in metastatic GC. In the study of Pourghasemian et al., mDCF and FOLFOX-4 were compared in advanced stage gastric adenocarcinoma patients, and no difference was found between the group in terms of the objective response rate (46.98\% vs. $35.1 \%$, respectively), OS ( $13.50 \pm 5.94$ months vs. $12.61 \pm 4.05$, respectively) [22]. In addition, while hematological side effects such as neutropenia, neutropenic fever, thrombocytopenia were more common in the mDCF arm, neuropathy was observed more frequently in the FOLFOX-4 arm [22]. Al-Batran et al. [23] compared FLO (oxaliplatin $85 \mathrm{mg} / \mathrm{m}^{2}$ and leucovorin $200 \mathrm{mg} / \mathrm{m}^{2}$, each as a two-hour intravenous infusion, followed by FU $2600 \mathrm{mg} / \mathrm{m}^{2}$ as a 24-hour continuous infusion every two weeks) and FLP (cisplatin $50 \mathrm{mg} / \mathrm{m}^{2}$ as a two-hour infusion every two weeks combined with leucovorin $200 \mathrm{mg} / \mathrm{m}^{2}$ as a two-hour infusion and $\mathrm{FU}$ $2000 \mathrm{mg} / \mathrm{m}^{2}$ as a 24-hour infusion every week for six weeks followed by a two-week rest) treatment regimens in their study and they found no difference between the FLO and FLP groups in terms of treatment response rates ( $25 \%$ vs. $35 \%$, respectively), OS ( 8.8 vs. 10.7 months, respectively), and PFS (6.0 vs. 3.1 months, respectively). In this study, treatment responses between the two groups were examined in patients who received $\mathrm{mDCF}$ and $\mathrm{mFOLFOX}-6$ as metastatic first-line therapy, and no difference was found in terms of treatment responses, median OS, and median PFS. Additionally, although dose reduction, delay of treatment, and neutropenic fever were numerically higher in the MDCF arm in our study, they did not reach statistical significance. Considering the above-mentioned studies comparing DCF and mDCF, it can be concluded that MDCF is non-inferior in terms of OS and PFS and its side effect profile is better than DCF.

In our study, the presence of peritoneal metastasis was evaluated as a significant prognostic factor in univariate analysis in terms of OS, but no statistical significance was reached in multivariate analysis. Similarly, in various studies, the presence of peritoneal metastasis in patients has been defined as a poor prognostic factor $[24,25]$. While there were differences between treatment arms regarding metastasis status (de novo vs recurrent), metastasis status has not been found to be a prognostic factor for OS both in univariate and multivariate analysis. In addition, age, sex, ECOG-PS, histological subtype, presence of liver metastasis, de novo, or recurrent metastasis, number of metastases were not included among prognostic factors associated with OS in this study.

The major limitations of the present study were that its retrospective nature and the relatively small number of patients. In addition, while evaluating the side effect profiles of the patients, apart from neutropenic fever, treatment delay and dose reduction, non-hematological side effects such as neuropathy, nausea, and vomiting could not be evaluated.

\section{Conclusions}

The present study demonstrated that proper patient selection for metastatic GC may give rise to comparable survival rates without increased toxicity. According to our data, the presence of comorbid disease was the major determining factor for the choice of the treatment regimen. Fluoropyrimidine and platinum-based combination therapies are the most commonly used regimens in the first-line treatment of metastatic GC. In addition, docetaxel can be added to the treatment in patients with a high tumor burden and relatively better performance status. In addition, although different modified doses were used in the studies, it could be shown that mDCF is noninferior to DCF. Finally, mFOLFOX-6 and mDCF had similar response rates, OS, PFS, and side effect profiles. Studies with larger numbers of patients and larger populations are needed. 


\section{Additional Information \\ Disclosures}

Human subjects: Consent was obtained or waived by all participants in this study. Health Science University, Ankara City Hospital issued approval E2-20-03. The study titled "Comparison of the Efficacies and Toxicities of mDCF and mFOLFOX-6 as First-Line Treatment in Metastatic Gastric Cancer" from Ankara City Hospital Medical Oncology Clinic was reviewed and it was approved unanimously in terms of ethics. Animal subjects: All authors have confirmed that this study did not involve animal subjects or tissue. Conflicts of interest: In compliance with the ICMJE uniform disclosure form, all authors declare the following: Payment/services info: All authors have declared that no financial support was received from any organization for the submitted work. Financial relationships: All authors have declared that they have no financial relationships at present or within the previous three years with any organizations that might have an interest in the submitted work. Other relationships: All authors have declared that there are no other relationships or activities that could appear to have influenced the submitted work.

\section{References}

1. Sitarz R, Skierucha M, Mielko J, Offerhaus GJA, Maciejewski R, Polkowski WP: Gastric cancer: epidemiology, prevention, classification, and treatment. Cancer Manag Res. 2018, 10:239-48. 10.2147/CMAR.S149619

2. Crew KD, Neugut AI: Epidemiology of gastric cancer. World J Gastroenterol. 2006, 12:354-62. 10.3748/wjg.v12.i3.354

3. Ma J, Shen H, Kapesa L, Zeng S: Lauren classification and individualized chemotherapy in gastric cancer . Oncol Lett. 2016, 11:2959-64. 10.3892/ol.2016.4337

4. Torre LA, Siegel RL, Ward EM, Jemal A: Global cancer incidence and mortality rates and trends - an update . Cancer Epidemiol Biomarkers Prev. 2016, 25:16-27. 10.1158/1055-9965.EPI-15-0578

5. Collaborators GBDSC: The global, regional, and national burden of stomach cancer in 195 countries, 19902017: a systematic analysis for the Global Burden of Disease study 2017. Lancet Gastroenterol Hepatol. 2020, 5:42-54. 10.1016/S2468-1253(19)30328-0

6. Jemal A, Bray F, Center MM, Ferlay J, Ward E, Forman D: Global cancer statistics. CA Cancer J Clin. 2011, 61:69-90. 10.3322/caac.20107

7. Ilson DH: Advances in the treatment of gastric cancer: 2019 . Curr Opin Gastroenterol. 2019, 35:551-4. 10.1097/MOG.0000000000000577

8. Van Cutsem E, Sagaert X, Topal B, Haustermans K, Prenen H: Gastric cancer. Lancet. 2016, 388:2654-64. 10.1016/S0140-6736(16)30354-3

9. Wagner AD, Unverzagt S, Grothe W, Kleber G, Grothey A, Haerting J, Fleig WE: Chemotherapy for advanced gastric cancer. Cochrane Database Syst Rev. 2010, CD004064. 10.1002/14651858.CD004064.pub3

10. Murad AM, Santiago FF, Petroianu A, Rocha PR, Rodrigues MA, Rausch M: Modified therapy with 5fluorouracil, doxorubicin, and methotrexate in advanced gastric cancer. Cancer. 1993, 72:37-41. 10.1002/1097-0142(19930701)72:1<37::aid-cncr2820720109>3.0.c0;2-p

11. Glimelius B, Ekström K, Hoffman K, et al.: Randomized comparison between chemotherapy plus best supportive care with best supportive care in advanced gastric cancer. Ann Oncol. 1997, 8:163-8. 10.1023/a:1008243606668

12. Hong YS, Song SY, Lee SI, et al.: A phase II trial of capecitabine in previously untreated patients with advanced and/or metastatic gastric cancer. Ann Oncol. 2004, 15:1344-7. 10.1093/annonc/mdh343

13. Mavroudis D, Kourousis C, Androulakis N, et al.: Frontline treatment of advanced gastric cancer with docetaxel and granulocyte colony-stimulating factor (G-CSF): a phase II trial. Am J Clin Oncol. 2000, 23:3414. 10.1097/00000421-200008000-00005

14. Sulkes A, Smyth J, Sessa C, et al.: Docetaxel (Taxotere) in advanced gastric cancer: results of a phase II clinical trial. EORTC Early Clinical Trials Group. Br J Cancer. 1994, 70:380-3. 10.1038/bjc.1994.310

15. Köhne CH, Catane R, Klein B, et al.: Irinotecan is active in chemonaive patients with metastatic gastric cancer: a phase II multicentric trial. Br J Cancer. 2003, 89:997-1001. 10.1038/sj.bjc.6601226

16. Yamada Y, Boku N, Mizusawa J, et al.: Docetaxel plus cisplatin and S-1 versus cisplatin and S-1 in patients with advanced gastric cancer (JCOG1013): an open-label, phase 3, randomised controlled trial. Lancet. 2019, 4:501-10. 10.1016/S2468-1253(19)30083-4

17. Bang YJ, Kang WK, Kang YK, et al.: Docetaxel $75 \mathrm{mg} / \mathrm{m}(2)$ is active and well tolerated in patients with metastatic or recurrent gastric cancer: a phase II trial. Jpn J Clin Oncol. 2002, 32:248-54. 10.1093/jjco/hyf057

18. Constenla M, Garcia-Arroyo R, Lorenzo I, Carrete N, Campos B, Palacios P: Docetaxel, 5-fluorouracil, and leucovorin as treatment for advanced gastric cancer: results of a phase II study. Gastric Cancer. 2002, 5:1427. $10.1007 / \mathrm{s} 101200200025$

19. Van Cutsem E, Moiseyenko VM, Tjulandin S, et al.: Phase III study of docetaxel and cisplatin plus fluorouracil compared with cisplatin and fluorouracil as first-line therapy for advanced gastric cancer: a report of the V325 Study Group. J Clin Oncol. 2006, 24:4991-7. 10.1200/JCO.2006.06.8429

20. Inal A, Kaplan MA, Kucukoner M, Isikdogan A: Docetaxel and Cisplatin Plus Fluorouracil compared with Modified Docetaxel, Cisplatin, and 5-Fluorouracil as first-line therapy for advanced gastric cancer: a retrospective analysis of single institution. Neoplasma. 2012, 59:233-6. 10.4149/neo_2012_030

21. Shah MA, Janjigian YY, Stoller R, et al.: Randomized multicenter phase ii study of modified docetaxel, cisplatin, and fluorouracil (DCF) versus DCF plus growth factor support in patients with metastatic gastric adenocarcinoma: a study of the US gastric cancer consortium. J Clin Oncol. 2015, 33:3874-9. 10.1200/JCO.2015.60.7465

22. Pourghasemian M, Danandeh Mehr A, Molaei M, Habibzadeh A: Outcome of FOLFOX and modified DCF chemotherapy regimen in patients with advanced gastric adenocarcinoma. Asian Pac J Cancer Prev. 2020, 21:2337-41. 10.31557/APJCP.2020.21.8.2337

23. Al-Batran SE, Hartmann JT, Probst S, et al.: Phase III trial in metastatic gastroesophageal adenocarcinoma 


\section{Cureus}

with fluorouracil, leucovorin plus either oxaliplatin or cisplatin: a study of the Arbeitsgemeinschaft Internistische Onkologie. J Clin Oncol. 2008, 26:1435-42. 10.1200/JCO.2007.13.9378

24. Chau I, Norman AR, Cunningham D, Waters JS, Oates J, Ross PJ: Multivariate prognostic factor analysis in locally advanced and metastatic esophago-gastric cancer--pooled analysis from three multicenter, randomized, controlled trials using individual patient data. J Clin Oncol. 2004, 22:2395-403. 10.1200/JCO.2004.08.154

25. Kienle P, Koch M: Are "micrometastases" of the peritoneum equivalent to distant metastases? . Dig Surg. 2002, 19:453-8. 10.1159/000067609 